\title{
EXPERIMENTAL AN D THEORETICAL SPECTROSCOPIC STUDY OF THIONE-THIOL TAUTOMERISM OF NEW HYBRIDES 1,3,4-OXADIAZOLE-2-THION WITH ACRIDINE-9(10H)-ONE
}

\author{
Yuriy Karpenko ${ }^{1, *}$, Lyudmila O melyanchik ${ }^{1}$, Tamara Panasenko ${ }^{1}$
}

https://doi.org/10.23939/chcht12.04.419

\begin{abstract}
The synthesis of new hybrides 1,3,4-oxadiazol2-thione with acridine $9(10 \mathrm{H})$-one is carried out. Their structure is confirmed by LC-MS, IR-, ${ }^{1} \mathrm{H}$ and ${ }^{13} \mathrm{C}$ NMRspectroscopy. The thione-thiol equilibrium was investigated in eight solvents with different relative permittivity with the help of UV-spectroscopy and quantum chemistry methods using DFT/B3LYP and HF bases. The results of the experimental calculations are in agreement with theoretical ones and have shown the prevalence of the thione. There were established centers for reactions with the mechanism $\mathrm{S}_{\mathrm{E}}$ and $\mathrm{A}_{\mathrm{E}}$, taking into account the electronic structural formulas and the results of calculating the atom charges of compounds.
\end{abstract}

Keywords: acridine-9(10H)-one, 1,3,4-oxadiazole, 1,3,4oxadiazole-2-thione, UV-spectroscopy, molecular orbitals, quantum-chemical calculations.

\section{Introduction}

One of the important problems of medical and organic chemistry is the creation of new highly active and safe medical substances. Justification of the search is also conditioned by the presence in some cases of undesirable side effects in the existing drugs and the acquirement of the resistance of microorganisms to them. Not only substances of natural origin but also new synthesized substances and chemical modification of existing active compounds are used to create bioactive molecules.

Acridine-9 $(10 H)$-one is a part of the alkaloid, acronicin, which was separated from Acronychia baueri in 1948 [1]. It has been found that it has a strong antitumor activity, and it is also a powerful molecule for suppressing the acute promyelocytic leukemia. Glypholin, another natural alkaloid, is a derivative of acridine-9(10H)-one and is the most potent molecule for inhibition of leukemic

\footnotetext{
${ }^{1}$ Zaporizhzhia National University

66, Zhukovsky St., 69600 Zaporizhzhia, Ukraine

karpenko.y.v@gmail.com

(c) Karpenko Yu., Omelyanchik L., Panasenko T., 2018
}

cells HL-60 of a human [2]. Several derivatives of acridine-9 $(10 H)$-one were found with the alkyl residue of the side chain attached to $N$-position, exhibiting antitumor and antibacterial activity. The research in vitro and in vivo of new pyridine acridones with anticancer activity is also known [3].

Publications of recent years [4] indicate the prospect of the search for biologically active substances in a series of 10-azolylmethylacridones with antibacterial, antimicrobial and fungicidal activity. Combining in one molecule two pharmacophore fragments - acridine$9(10 H)$-one and azole heterocycles, bound by a methylene or ethylene bridge, can lead to the production of compounds that exhibit a wide range of biological activity.

These compounds have many unique pharmacological properties due to the relatively high molecular weight, flat tricyclic acridone nucleus, hydrophilicity of cyclic ketone group $\left(\mathrm{C}_{9}=\mathrm{O}\right)$ and ethanolic residue [5]. The presence of 1,3,4-oxadiazole fragment linked with a methylene bridge enhances the antiviral and antibacterial activity of the compound and reduces acute toxicity and minimal side effects.

In recent years, intra- or intermolecular proton transfer has been a topic of much interest because of its importance in many chemical and biological processes [69]. A large number of theoretical and experimental investigations have been carried out to enrich the information about the possible mechanisms of proton transfer and tautomeric equilibria of relevant properties connected with the proton transfer [10-14]. In particular, the role played by the solvent in intra- or intermolecular proton transfer reactions is known to be decisive [15].

Mercapto-azoles can exist in two major tautomeric forms that exhibit different reactivities, as demonstrated for polymerization processes, metal complexation and substitution reactions [16-22]. In this respect, there is a growing interest in the scientific communities to the experimental and theoretical investigations of thione-thiol tautomeric equilibrium of 1,3,4-oxadiazole-2-thione derivatives and their electronic structure [23-26]. 


\section{Experimental}

\subsection{G eneral}

All starting materials were purchased from SigmaAldrich. Melting points were determined by the melting method in the capillary [27]. The individuality of the compounds was controlled by the TLC method on a Silufol plate UV-254 in the eluent system butanol:ethanolic acid:water (5:3:2). The UV-lamp was used as a developer. The elemental composition of new compounds is established on the elemental analyzer ELEMENTAR Vario EL cube (sulfanilamide as a standard). The UV-spectra were taken on a Shimadzu UV-1800 using the UVProbe 2.4.6 spectrum interpretation software. IR-spectra were taken on a Bruker Alpha Spectrophotometer in a range of $7500-400 \mathrm{~cm}^{-1}$ using the ATR prefix (direct injection). ${ }^{1} \mathrm{H}$ and ${ }^{13} \mathrm{C}$ NMR spectra were recorded on "Bruker AC-400" (400 MHz) using a mixture of DMSO- $\mathrm{d}_{6}$ as a solvent and tetramethylsilane (TMS) as an internal standard. Chemical shifts values are reported in ppm units with use of $\delta$ scale. LC-MS spectra were recorded by a high-performance liquid chromatography module of the HPLC system for Agilent 1260 Infinity and a proton-ionization diode-matrix probe.

\subsection{Synthesis Procedure}

Synthesis of 10-((5-mercapto-1,3,4-oxadiazole-2$y l)$ methyl)-2R-acridine-9(10H)-ones.

Butyl esters of 2-substituted 2-(9-oxoacridine10(9H)-yl)ethane acids (2, 2a) were obtained by alkylation of the corresponding acridine- $9(10 H)$-ones (1, 1a) with butyl chloroacetate in DMF at $403 \mathrm{~K}$ with sodium hydride (Scheme 1) [28].
It is known that hydrazides of carboxylic acids, due to their reactivity, are widely used for the synthesis of various nitrogen-containing heterocyclic systems [29-32]. The most common way to obtaine hydrazides of carboxylic acids is the hydrazinolysis reaction of complex esters of the corresponding acids [29-31, 33]. Therefore, we used butyric esters of 2-(2R-9-oxoacridine- $10(9 \mathrm{H})$ yl)ethane acids $(\mathbf{2}, \mathbf{2 a})$ for the synthesis of hydrazides $(\mathbf{3}$, 3a). The choice of butyl esters as starting compounds in the synthesis of hydrazides is due to the fact that butyl ester 2-(2R-9-oxoacridine-10(9H)-yl)ethane acids $(\mathbf{2}, \mathbf{2 a})$ is a semi-product of commercially produced antiviral drugs "Cycloferon ${ }^{\circledR}$ " and "Neovir ${ }^{\circledR}$ ".

One of the well-known methods for the synthesis of 5-substituted-1,3,4-oxadiazole-2-thiols is the cyclization of the carboxylic acid hydrazides under the action of carbon disulfide [34, 35]. Therefore, the obtained 2-(2R-9-oxoacridine-10(9H)-yl)acetohydrazides (3, 3a) were cyclized under the action of carbon disulfide from potassium hydroxide in ethanol (Scheme 1).

General procedure for the synthesis of 10-((5mercapto-1,3,4-oxadiazole-2-yl)methyl)-2R-acridine$9(10 H)$-ones $(4,4 a)$.

$0.56 \mathrm{~g}(0.01 \mathrm{~mol})$ of potassium hydroxide and $2.41 \mathrm{ml}(0.04 \mathrm{~mol})$ of carbon disulfide were dissolved in $30 \mathrm{ml}$ of ethanol, and $2.67 \mathrm{~g}(0.01 \mathrm{~mol})$ of 2-(2R-9oxoacridine-10(9H)-yl)acetohydrazide in $30 \mathrm{ml}$ of ethanol were added. The reaction mixture was boiled for $24 \mathrm{~h}$ on a magnetic stirrer with a reflux condenser to dissolve the 2-(2R-9-oxoacridine-10(9H)-yl)acetohydrazide precipitate. The precipitate was filtered off, the filtrate was left to evaporate in a porcelain cup; crystals in a porcelain cup dissolved in water and acidify the solution with a $5 \%$ solution of hydrochloric acid to $\mathrm{pH} 6$. The compounds were crystallized by re-precipitation from an aqueous solution using sodium hydroxide and ethanolic acid.

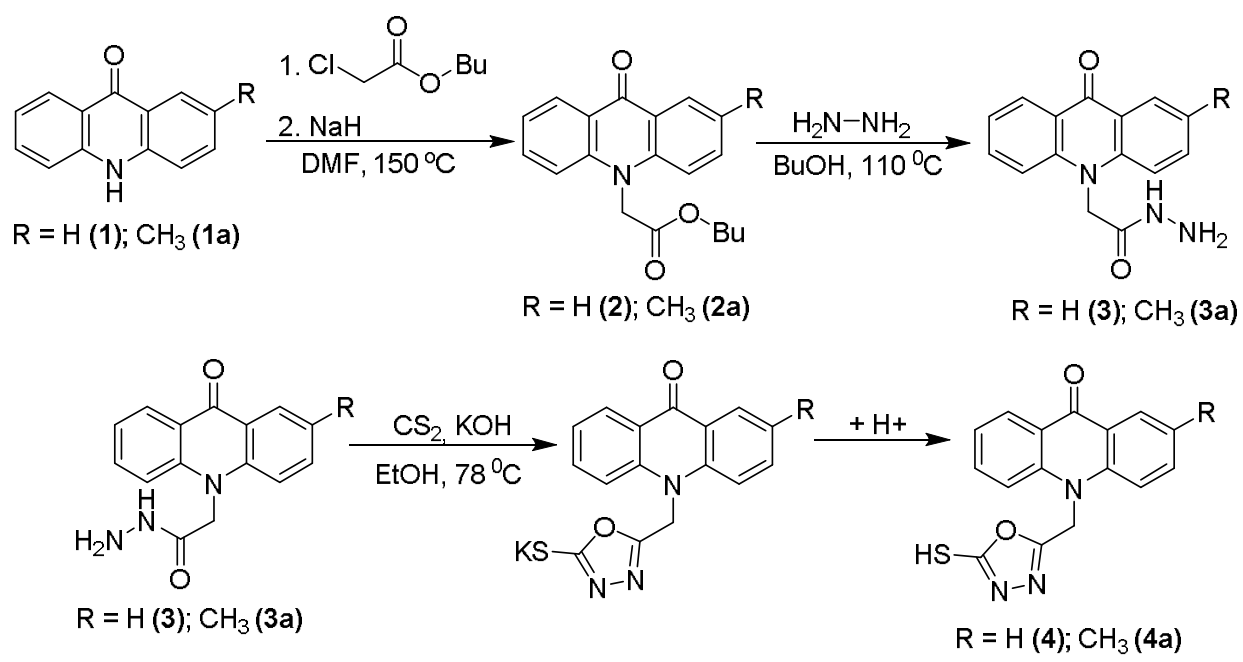

Scheme 1. Synthesis of 10-((5-mercapto-1,3,4-oxadiazole-2-yl)methyl)-2R-acridine-9 (10H)-ones 
10-((5-mercapto-1,3,4-oxadiazole-2-yl)methyl)acridine-9(10H)-one (4). Yield 90\%, mp 441-443 K. ${ }^{1} \mathrm{H}$ NMR spectrum, $\delta$, ppm: $5.4 \mathrm{~s}\left(2 \mathrm{H}, \mathrm{CH}_{2}\right) ; 7.3-8.5 \mathrm{~m}$ $\left(7 \mathrm{H}, \mathrm{CH}_{\mathrm{ar}}\right) ; 11.8 \mathrm{~s}(1 \mathrm{H}, \mathrm{NH}) .{ }^{13} \mathrm{C}$ NMR spectrum, $\delta$, ppm: $48.8\left(\mathrm{CH}_{2}\right) ; 114.6,114.6,121.5,121.5,123.6,123.6$, $130.1,130.1,134.4,134.4,143.4,143.4\left(\mathrm{C}_{\mathrm{ar}}\right.$, acridine9(10H)-one); 156.1, 169.2 ( $\mathrm{C}_{\mathrm{ar}}, 1,3,4$-oxadiazole); 178.2 (C-O). IR-spectrum, $v, \mathrm{~cm}^{-1}: 1290.00(\mathrm{C}=\mathrm{S}) ; 670.55$, $738.46,928.24,1148.51,1181.74,1266.70, \quad\left(=\mathrm{CH}_{\mathrm{ar}}\right.$, acridine-9(10H)-one); $1071.47(\mathrm{~N}-\mathrm{N}), 1504.44,1554.46$ (C-NH, 1,3,4-oxadiazole); $1590.40\left(\mathrm{C}=\mathrm{O}_{\text {ap }}\right)$. IR-spectrum (potassium salt), $v, \mathrm{~cm}^{-1}: 1352.06\left(=\mathrm{CH}_{\text {ar }}\right) ; 1590.14(\mathrm{C}-$ $\left.\mathrm{O}_{\mathrm{ar}}\right) ; 3211.98(\mathrm{C}-\mathrm{S}-\mathrm{K}) . \mathrm{R}_{\mathrm{f}}=0.47$. LC-MS spectrum, $\mathrm{m} / \mathrm{z}$, $\left(\mathrm{I}_{\mathrm{rel}}, \%\right): 310[\mathrm{M}+\mathrm{H}]^{+}$. Found, \%: C 62.12; H 3.58; N, 13.58; $\mathrm{S} 10.36$. $\mathrm{C}_{16} \mathrm{H}_{11} \mathrm{~N}_{3} \mathrm{O}_{2}$ S. Calcd., \%: C 62.42; H 3.48; N 13.50; S 10.40

10-((5-mercapto-1,3,4-oxadiazole-2-yl)methyl)-2methylacridine-9(10H)-one (4a). Yield $92 \%$, mp 445$447 \mathrm{~K} .{ }^{1} \mathrm{H}$ NMR spectrum, $\delta$, ppm: $2.4 \mathrm{~s}\left(3 \mathrm{H}, \mathrm{CH}_{3}\right) ; 5.4 \mathrm{~s}$ $\left(2 \mathrm{H}, \mathrm{CH}_{2}\right) ; 7.1-8.5 \mathrm{~m}\left(7 \mathrm{H}, \mathrm{CH}_{\mathrm{ar}}\right) ; 11.8 \mathrm{~s}(1 \mathrm{H}, \mathrm{NH})$. ${ }^{13} \mathrm{C}$ NMR spectrum, $\delta$, ppm: $20.1\left(\mathrm{CH}_{3}\right) ; 48.8\left(\mathrm{CH}_{2}\right)$; $114.6,114.8,120.8,123.6,124.5,126.7,130.1,130.1$, $134.4,137.6,143.4,143.4$ ( $\mathrm{C}_{\mathrm{ar}}$, acridine-9(10H)-one); 156.1, $169.2\left(\mathrm{C}_{\mathrm{ar}}, 1,3,4\right.$-oxadiazole); 179.7 (C-O). IRspectrum, $v, \mathrm{~cm}^{-1}: 1324.67(\mathrm{C}=\mathrm{S}) ; 679.26,745.74$, 930.77, 1139.50, 1270.15, (= $\mathrm{CH}_{\mathrm{ar}}$, acridine-9(10H)-one); $1070.17 \quad(\mathrm{~N}-\mathrm{N}), \quad 1508.38, \quad 1552.22 \quad(\mathrm{C}-\mathrm{NH}, \quad 1,3,4-$ oxadiazole); $1585.90\left(\mathrm{C}=\mathrm{O}_{\mathrm{ar}}\right)$. IR-spectrum (potassium salt), $v, \mathrm{~cm}^{-1}:$ 751.29, 1180.98, 1264.75, 1408.36, 1494.38, $1555.77\left(\mathrm{C}=\mathrm{O}_{\mathrm{ar}}\right), 3212.08(\mathrm{C}-\mathrm{S}-\mathrm{K}) . \mathrm{R}_{\mathrm{f}}=0.45$. LC-MS, $\mathrm{m} / \mathrm{z},\left(\mathrm{I}_{\text {rel }}, \%\right): 324[\mathrm{M}+\mathrm{H}]^{+}$. Found, \%: C 63.10; H 4.15; N 13.04; S 9.81. $\mathrm{C}_{17} \mathrm{H}_{13} \mathrm{~N}_{3} \mathrm{O}_{2}$ S. Calcd., \%: C 63.14; H, 4.05; N 12.99; S 9.91.

\subsection{Computer $Q$ uantum-Chemical Methods}

All calculations were performed using Gauss-View 5.0.8 [36] and Gaussian 09 Revesio-A.02-SMP [37] software rendering. The geometries of the ground state were fully optimized using the most popular B3LYP method [38], applying 6-31-G (d, p) [39] of base sets without symmetry constraints and using default convergence criteria. After optimizing the geometry, frequency calculations were followed. Consequently, the stationary structures are confirmed by verifying that all the main states have only real frequencies, and all transition states have only one imaginary frequency using the same method and established basis used to optimize geometry. The approximation of the equations of the polarizing continuum (IEEPCM) [40] was used to consider the influence of a bulk solution at the same level. The charge of atoms was calculated by the semi-empirical quantum-chemical method of Hückel [41].

\section{Results and Discussion}

Tautomerism is a dynamic isomerism because tautomers can be easily converted one into another in solutions. The UV-spectrophotometric method can be used successfully to study equilibrium processes in cases where the chromatophoric group undergoes isomerization, so that a double bond migration occurs. Such a process is accompanied by significant changes in electronic spectra. Thus, in our case, there is a transition from the chromonate of the thione group to the isolated double bond of the substituted thiol group with a thione-thiol tautomerism (Fig. 1).

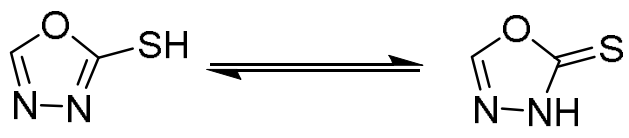

Fig. 1. Thione-thiol tautomerism of the isolated fragment of 1,3,4-oxadiazole-2(3H)-thione

Thus, it can be predicted that they may exhibit the thione-thiol tautomerism based on the structure of the investigative substances. This fact was established with the help of the LC-DMD-MS system, which showed the presence of the corresponding peaks of ions that matches to the ionized tautomer compounds (Figs. 2 and 3). According to the obtained LC-MS, it is obvious that the fragment of the oxadiazole ring will ionize first, namely, the $=S$ substituent. In the future ionization undergoes a fragment of acridine-9 $(10 H)$ one, namely a cyclic ketone group $\left(\mathrm{C}_{9}=\mathrm{O}\right)$.

Knowing of the relative stability of tautomeric forms, as well as the transformation from one tautomeric form to another, is important in terms of structural chemistry. In addition, knowing of how energy of tautomerization changes in various solvents, one can understand the influence of solvents on molecular stability and reactivity. In this study, we focus our attention on thione-thiol tautomerism, both in the gas phase and in the solution. As it is known [42], monocyclic heteroaromatic compounds containing three hetero atoms in a fivemembered ring exhibit a single band of moderate intensity near the short-wave limit of the near-ultraviolet light. The molecular charts of 2,5-diaryl-substituted 1,3,4-oxadiazole give an idea of the distribution of electron density in heterocycle and related radicals. Heterocycle is a strong electron acceptor [43].

The similarity in the nature of the UV-spectra absorption of 2,5-diaryl-substituted 1,3,4-oxadiazole in aliphatic carbohydrates at room temperature and the spectra of such diaryl-substituted ethylene suggest the same type of conjugation in these molecular systems. It means that the contribution of the ethylene group in the $\pi$-conjugation of this type molecules is equivalent to 2,5-diaryl-substituted 1,3,4-oxadiazole, but the position of 
the absorption maxima is different. $N-\pi^{*}$ bands appear in the spectra of these compounds. The extension of the conjugation chain in aryl radicals of diaryloxydiazoles leads to a significant shift of absorption spectra towards longer waves, the quantum yield of fluorescence increases.

From literary sources $[10,15,26,42]$ it is known that aza-analogues of furan have a maximum absorption below $220 \mathrm{~nm}$, but have not been sufficiently studied. The corresponding 2-methyl-1,3,4-oxadiazole has an absorption band $\lambda(\max )$ of $206 \mathrm{~nm}(\lg \varepsilon=2.62)$ in methanol. In addition, $\pi$-excessive five-membered heterocycles with $=\mathrm{S}$ substituent, acting as an electron donor to 1,3,4-oxadiazole, and correspondingly, will shift to the long wave region of the spectrum.
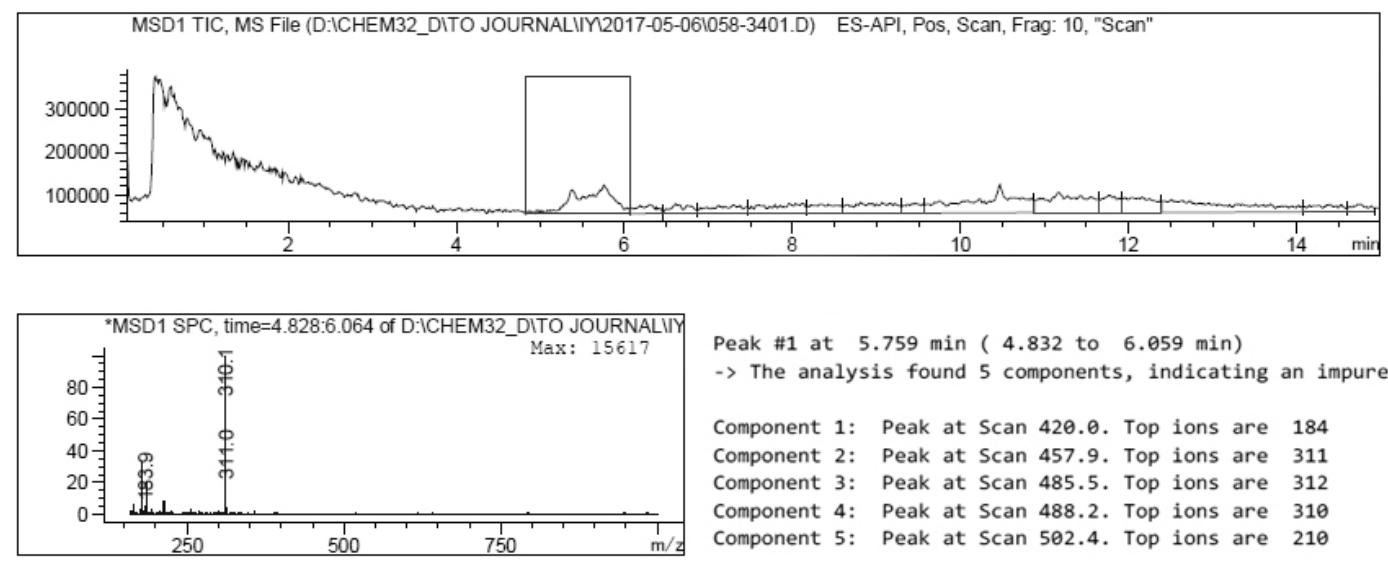

Peak \#1 at $5.759 \mathrm{~min}(4.832$ to $6.059 \mathrm{~min}$ )

-> The analysis found 5 components, indicating an impure peak

Component 1: Peak at Scan 420.0. Top ions are 184 Component 2: Peak at Scan 457.9. Top ions are 311 Component 3: Peak at Scan 485.5. Top ions are 312

Component 4: Peak at Scan 488.2. Top ions are 310

Component 5: Peak at Scan 502.4. Top ions are 210

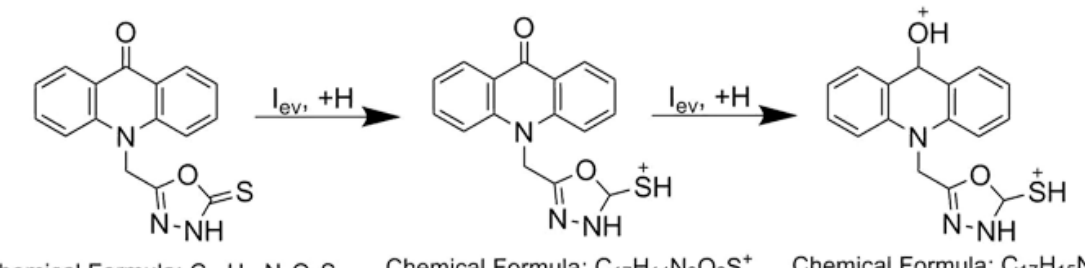

Chemical Formula: $\mathrm{C}_{16} \mathrm{H}_{11} \mathrm{~N}_{3} \mathrm{O}_{2} \mathrm{~S}$

Chemical Formula: $\mathrm{C}_{17} \mathrm{H}_{14} \mathrm{~N}_{3} \mathrm{O}_{2} \mathrm{~S}^{+}$

Molecular Weight: 311

Molecular Weight: 312

Fig. 2. LC-MS of the compound 10-((5-mercapto-1,3,4-oxadiazole-2-yl)methyl)-acridine-9(10H)-one (4)

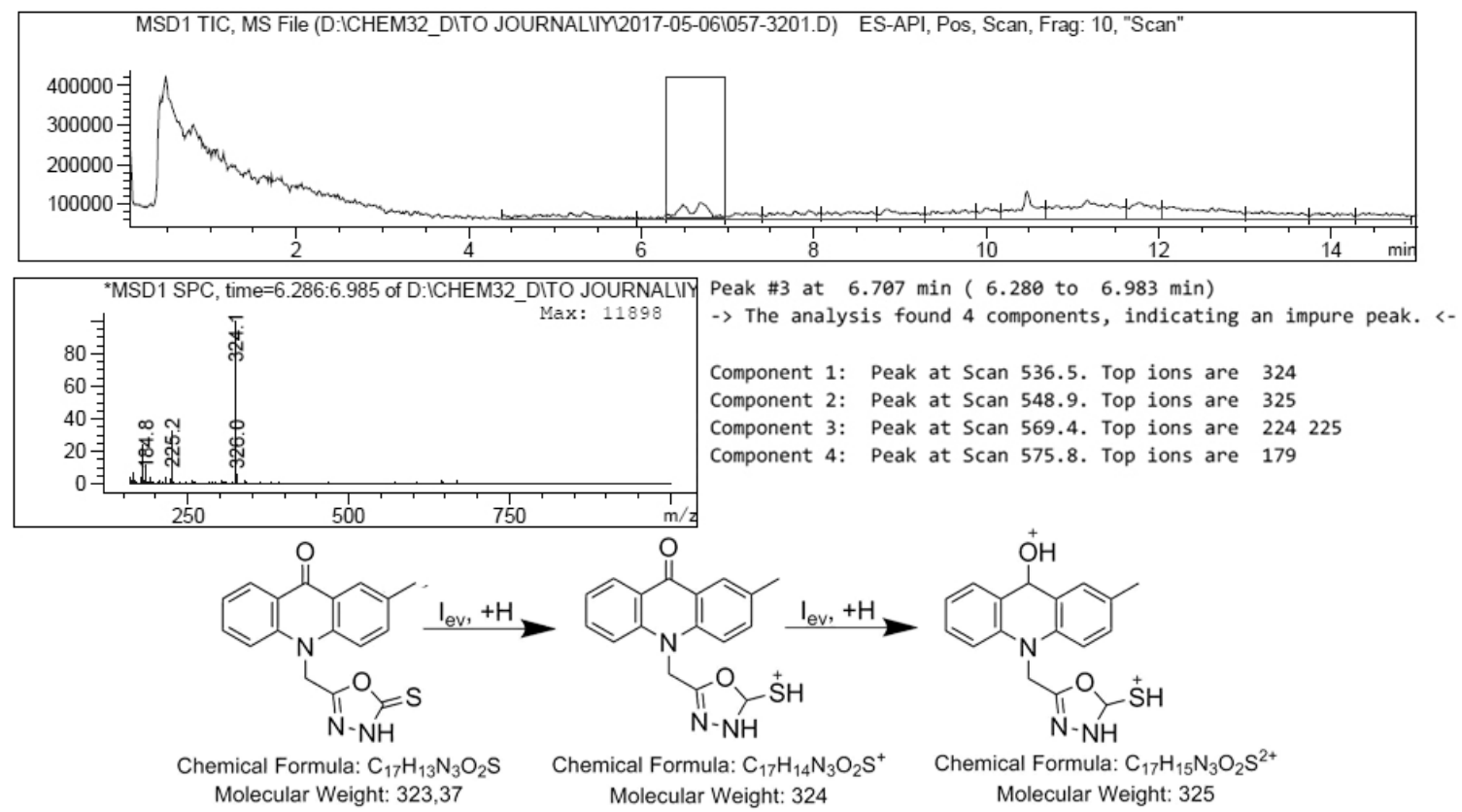

Fig. 3. LC-MS of the compound 10-((5-mercapto-1,3,4-oxadiazole-2-yl)methyl)-2-methylacridine-9 (10H)-one (4a) 
In the acridine- $9(10 H)$-one and its $N$-substituted levels, the $S_{n \pi^{*}}$ and $T_{n \pi^{*}}$ states are located above the $S_{n \pi^{*}}$ state level. Therefore, the long wave band in the absorption spectrum is an intensive $n-\pi^{*}$ band. Solutions of these compounds in normal hydrocarbons have a weak fluorescence, and in polar solvents - a very bright fluorescence. At $77 \mathrm{~K}$, a prolonged $n-\pi^{*}$ phosphorescence, which is more long-wavelength in alcohol than in hexane, is typical of solutions, along with fluorescence. Two absorption bands are observed in the ultraviolet spectrum deposited in the electronic base of the NIST Chemistry WebBook [44] acridine-9(10H)-one in ethanol: $\lambda(\max )$ $257 \mathrm{~nm}(\lg \varepsilon=4.8)$ and the wide absorption band in the range of $380-410 \mathrm{~nm}(\lg \varepsilon=4)$.

The interpretation of the existence of possible forms of thione-thiol tautomerism of compounds and an explanation of the relation between absorption properties and structure in our case are based on the comparison of $\mathrm{UV}$-spectra of the corresponding compounds in solvents of different polarity and different $\mathrm{pH}$ values of the medium.

As it can be seen from the data (Table 1), the UVspectra of 10-((5-mercapto-1,3,4-oxadiazole-2-yl)methyl)acridine- $9(10 H)$-one in water, $0.1 \mathrm{M} \mathrm{HCl}, 0.1 \mathrm{M} \mathrm{NaOH}$, ethanol and chloroform are characterized by the same maximum absorption band (253-254 nm) and a high molecular extinction coefficient characteristic of $n \rightarrow \pi^{*}$ transitions by the addition of aromatic nuclei - acridine9(10H)-one and 1,3,4-oxadiazole.

The maximum absorption band in $1 \mathrm{M} \mathrm{H}_{2} \mathrm{SO}_{4}$ appears at $197 \mathrm{~nm}$, which is characteristic of the $n \rightarrow \pi^{*}$ transition for the group $\mathrm{C}-\mathrm{S}-$, which corresponds to the thiol form of the compound. The bands that appear in water, $0.1 \mathrm{M} \mathrm{HCl}$, ethanol and $n$-hexanes are almost identical $(213,212.5,216$ and $210 \mathrm{~nm}$, respectively) and have a lower molecular extinction coefficient, indicating the grouping of $\mathrm{C}=\mathrm{S}$ corresponding to thionic form of the compound. It should be noted that in $n$-hexane, in which the fluctuations of the fine structure of matter appear, the maximum absorption is $216 \mathrm{~nm}$, which uniquely corresponds to the thione form of the compound. These bands are absent in chloroform and acetone. In alkaline solution, unambiguously, the compound is in the thiol form, but on the UV-spectra we can see the bathochromic shift of the spectrum toward the long-wave region due to the appearance of the apparent color of the solution.

The absorption band in the range of $386-399 \mathrm{~nm}$ is the result of $n \rightarrow \pi^{*}$ transitions of electrons, i.e., ${ }^{1} \mathrm{~L}_{\mathrm{b}}$ band, which is provided by the local excitation of the electrons of the cyclic ketone group in the acridine- $9(10 H)$-one cycle. Therefore, in the UV-spectrum with acetone, this band is maximal and appears in all other spectra. But significant hypsochromic shifts occur in $n$-hexane, because the structure of the test substance exhibits a fine oscillatory structure.

In acidic solutions and $n$-hexanes, waves can be observed in the wide range of $223-293.5 \mathrm{~nm}$, which is the result of $p$ - $\pi$ conjugation between acridine-9(10H)-one and 1,3,4-oxadiazole. This is due to the interaction of the unmatched pairs of $\pi$-electrons in both cycles, which leads to the formation of a single delocalized electron cloud, which is $p-\pi$ conjugation. Probably it depends on the increase in the strength of the acceptor properties of 1,3,4-oxadiazole in these solvents.

The UV-spectrum of the researched substance exhibits a more advanced vibrational structure in polar solvents than in non-polar ones. This follows from the appearance of a clear blue or blue violet fluorescence of compounds, which is consistent with the literature data $[42,43]$.

In theoretical spectroscopic studies of the compound 10-((5-mercapto-1,3,4-oxadiazole-2-yl)methyl)-acridin-

$9(10 H)$-one in polar solvents (Table 2), one can see the consideration of a molecule in general, as the creation of the effect of $p$ - $\pi$ conjugation of two heterocycles - acridine9(10H)-one and 1,3,4-oxadiazole. The greatest contribution according to the calculations is $n \rightarrow \pi^{*}-$ the transition of the cyclic ketone group of the acridone ring, which is the maximum of the bend of the UV-spectrum line. The thione form of this compound appears itself in the range of $323-327 \mathrm{~nm}$, and has the least power of an oscillator, but the greatest energy for the transition of electrons.

It can be clearly stated that there is the stabilization of the acridone ring and the establishment of an unambiguous thione-thiol tautomerism in the study of UV-spectra of the compound 10-((5-mercapto-1,3,4oxadiazole-2-yl)methyl)-2-methylacridine-9(10H)-one

(Table 3) containing 2-position donor methyl group. For all solutions, except for acetone and $1 \mathrm{M} \mathrm{H}_{2} \mathrm{SO}_{4}$, the same characteristic absorption band $(255-258.5 \mathrm{~nm})$ and a high molecular extinction coefficient corresponding to $n \rightarrow \pi^{*}$ transitions by the addition of aromatic nuclei - acridine9(10H)-one and 1,3,4-oxadiazole - are the same. In aqueous solutions, the action of the thione form is not shown at all, and the 1,3,4-oxadiazole ring is completely superimposed on the absorption band of acridine- $9(10 H)$ one and the $p-\pi$ subunit of heterocycles increases.

The maximum absorption band in $1 \mathrm{M} \mathrm{H}_{2} \mathrm{SO}_{4}$ is shown at $196 \mathrm{~nm}$, which is characteristic for the $n \rightarrow \pi^{*}$ transition for the group $\mathrm{C}-\mathrm{S}-$, which corresponds to the thiol form of the compound. The bands exhibiting in $0.1 \mathrm{M}$ $\mathrm{HCl}$, ethanol and chloroform are almost the same (201.5, 202.5 and $205 \mathrm{~nm}$, respectively) and have a lower molecular extinction coefficient, indicating a $\mathrm{C}=\mathrm{S}$ group that corresponds to the thionic form of the compound. In alkaline solution, unambiguously, the compound is in the thiol form, but on the UV-spectra, we can see the bathochromic shift of the spectrum toward the long-wave area due to the appearance of the apparent color of the solution.

It can be argued that the compound exists preferably in the form of a thione in neutral solutions (water, ethanol, $n$-hexane, chloroform), $\mathrm{b}$ ut in alkaline $(0.1 \mathrm{M} \mathrm{NaOH})$ and acidic solutions $(0.1 \mathrm{M} \mathrm{HCl}$ and $1 \mathrm{M}$ $\mathrm{H}_{2} \mathrm{SO}_{4}$ ) shows a more thiol form. 
Experimental spectroscopic study

of 10-((5-mercapto-1,3,4-oxadiazole-2-yl)methyl)-acridine-9(10H)-one (4)

\begin{tabular}{|c|c|c|c|c|}
\hline $\begin{array}{c}\text { Concentration, mol/l } \\
\text { solvent (relative permittivity) }\end{array}$ & $\lambda, \mathrm{nm}$ & $\varepsilon, 1 \cdot \mathrm{mol}^{-1} \cdot \mathrm{cm}^{-1}$ & $\lg \varepsilon$ & Electron transition \\
\hline \multirow{4}{*}{$\begin{array}{c}4.46 \cdot 10^{-5} \\
\text { water } \\
(78.30)\end{array}$} & 213 & 18094 & 4.26 & $n \rightarrow \pi^{*}$ transition \\
\hline & $254.5(\max )$ & 50002 & 4.70 & $n \rightarrow \pi^{*}$ transition \\
\hline & 388.5 & 7556 & 3.87 & $n \rightarrow \pi^{*}$ transition \\
\hline & 399 & 7735 & 3.88 & $n \rightarrow \pi^{*}$ transition \\
\hline \multirow{5}{*}{$\begin{array}{c}4.49 \cdot 10^{-6} \\
0.1 \mathrm{M} \mathrm{HCl} \\
(\approx 100[44])\end{array}$} & 212.5 & 10468 & 4.02 & $n \rightarrow \pi^{*}$ transition \\
\hline & 254.5 (max) & 50111 & 4.7 & $n \rightarrow \pi^{*}$ transition \\
\hline & 293.5 & 1559 & 3.19 & $p-\pi$ conjugation \\
\hline & 386.5 & 7572 & 3.87 & $n \rightarrow \pi^{*}$ transition \\
\hline & 399.5 & 7572 & 3.87 & $n \rightarrow \pi^{*}$ transition \\
\hline \multirow{5}{*}{$\begin{array}{l}4.49 \cdot 10^{-6} \\
1 \mathrm{M} \mathrm{H}_{2} \mathrm{SO}_{4} \\
\quad(\approx 130)\end{array}$} & $197(\max )$ & 69487 & 4.84 & $n \rightarrow \pi^{*}$ transition \\
\hline & 224.5 & 65256 & 4.81 & $p-\pi$ conjugation \\
\hline & 254.5 & 33853 & 4.53 & $n \rightarrow \pi^{*}$ transition \\
\hline & 387 & 4677 & 3.67 & $n \rightarrow \pi^{*}$ transition \\
\hline & 399.5 & 4899 & 3.69 & $n \rightarrow \pi^{*}$ transition \\
\hline \multirow{3}{*}{$\begin{array}{l}5.48 \cdot 10^{-5} \\
0.1 \mathrm{M} \mathrm{NaOH} \\
\quad(\approx 80)\end{array}$} & 216 & 16569 & 4.22 & $n \rightarrow \pi^{*}$ transition \\
\hline & 255 (max) & 50127 & 4.7 & $n \rightarrow \pi^{*}$ transition \\
\hline & 397.5 & 8394 & 3.92 & $\mathrm{n} \rightarrow \pi^{*}$ transition \\
\hline \multirow{4}{*}{$\begin{array}{l}6.56 \cdot 10^{-5} \\
n \text {-hexane } \\
(1.88)\end{array}$} & $216(\max )$ & 16570 & 4.22 & $\mathrm{n} \rightarrow \pi^{*}$ transition \\
\hline & 223 & 14558 & 4.16 & $p-\pi$ conjugation \\
\hline & 251 & 5793 & 3.76 & $n \rightarrow \pi^{*}$ transition \\
\hline & 333.5 & 366 & 2.56 & $n \rightarrow \pi^{*}$ transition \\
\hline \multirow{4}{*}{$\begin{array}{c}1.67 \cdot 10^{-5} \\
96 \% \text { ethanol }(24.55)\end{array}$} & 210 & 35449 & 4.55 & $n \rightarrow \pi^{*}$ transition \\
\hline & 254.5 (max) & 50060 & 4.7 & $n \rightarrow \pi^{*}$ transition \\
\hline & 378.5 & 7425 & 3.87 & $n \rightarrow \pi^{*}$ transition \\
\hline & 395 & 8982 & 3.95 & $n \rightarrow \pi^{*}$ transition \\
\hline \multirow{2}{*}{$\begin{array}{c}2.24 \cdot 10^{-5} \\
\text { chloroform }(4.81)\end{array}$} & 253 (max) & 50134 & 4.7 & $n \rightarrow \pi^{*}$ transition \\
\hline & 386 & 9688 & 3.98 & $n \rightarrow \pi^{*}$ transition \\
\hline \multirow{2}{*}{$\begin{array}{c}8.2 \cdot 10-5 \\
\text { acetone }(20.56)\end{array}$} & 372 & 9546 & 3.98 & $n \rightarrow \pi^{*}$ transition \\
\hline & $387.5(\max )$ & 12585 & 4.09 & $n \rightarrow \pi^{*}$ transition \\
\hline
\end{tabular}

Table 2

Theoretical spectroscopic study of 10-((5-mercapto-1,3,4-oxadiazole-2-yl)methyl)-acridine-9(10H)-one (4) in Gaussian program

\begin{tabular}{|c|c|c|c|c|c|c|}
\hline \multirow[b]{2}{*}{ Solvent } & \multicolumn{3}{|c|}{ Thione form } & \multicolumn{3}{|c|}{ Thiol form } \\
\hline & $\lambda, \mathrm{nm}$ & $\begin{array}{c}\text { Transition energy } \\
\Delta E, \mathrm{eV}\end{array}$ & Force oscillator $f$ & $\lambda, \mathrm{nm}$ & $\begin{array}{c}\text { Transition energy } \\
\Delta E, \mathrm{eV}\end{array}$ & Force oscillator $f$ \\
\hline \multirow{3}{*}{ Acetone } & 327.18 & 3.7895 & 0.0066 & 324.02 & 3.8265 & 0.0003 \\
\hline & 340.20 & 3.6445 & 0.0071 & 346.44 & 3.5788 & 0.0108 \\
\hline & 363.09 & 3.4147 & 0.1079 & 360.12 & 3.4428 & 0.1051 \\
\hline \multirow{3}{*}{ Water } & 326.32 & 3.7995 & 0.0059 & 323.17 & 3.8365 & 0.0003 \\
\hline & 339.32 & 3.6539 & 0.0057 & 345.53 & 3.5882 & 0.0085 \\
\hline & 363.12 & 3.4144 & 0.1082 & 360.31 & 3.4411 & 0.1060 \\
\hline \multirow{3}{*}{ Chloroform } & 330.17 & 3.7552 & 0.0094 & 327.38 & 3.7872 & 0.0004 \\
\hline & 343.21 & 3.6124 & 0.0151 & 349.35 & 3.5490 & 0.0290 \\
\hline & 363.34 & 3.4124 & 0.1019 & 359.89 & 3.4451 & 0.0916 \\
\hline \multirow{3}{*}{ Ethanol } & 326.99 & 3.7917 & 0.0065 & 323.82 & 3.8288 & 0.1059 \\
\hline & 340.00 & 3.6466 & 0.0067 & 346.24 & 3.5809 & 0.0102 \\
\hline & 363.14 & 3.4143 & 0.1085 & 360.21 & 3.4420 & 0.0003 \\
\hline
\end{tabular}


Experimental and Theoretical Spectroscopic Study of Thione-Thiol Tautomerism of $\mathrm{N}$ ew Hybrides...

Table 3

Experimental spectroscopic study

of 10-((5-mercapto-1,3,4-oxadiazole-2-yl)methyl)-2-methylacridine-9(10H)-one (4a)

\begin{tabular}{|c|c|c|c|c|}
\hline $\begin{array}{l}\text { Concentration mol/l; solvent } \\
\text { (relative permittivity) }\end{array}$ & $\lambda, \mathrm{nm}$ & $\varepsilon, 1 \cdot \mathrm{mol}^{-1} \cdot \mathrm{cm}^{-1}$ & $\lg \varepsilon$ & Electron transition \\
\hline \multirow{3}{*}{$\begin{array}{c}4.46 \cdot 10^{-5} \\
\text { water } \\
(78.30)\end{array}$} & $258.5(\max )$ & 1726 & 3.24 & $n \rightarrow \pi^{*}$ transition \\
\hline & 340 & 67.3 & 1.83 & $p-\pi$ conjugation \\
\hline & 404.5 & 336 & 2.53 & $n \rightarrow \pi^{*}$ transition \\
\hline \multirow{2}{*}{$\begin{array}{c}4.49 \cdot 10^{-6} \\
0.1 \mathrm{M} \mathrm{HCl}(\approx 100)\end{array}$} & $201.5(\max )$ & 34967 & 4.54 & $n \rightarrow \pi^{*}$ transition \\
\hline & 278 & 5568 & 3.75 & $n \rightarrow \pi^{*}$ transition \\
\hline \multirow{3}{*}{$\begin{array}{l}4.49 \cdot 10^{-6} \\
1 \mathrm{M} \mathrm{H}_{2} \mathrm{SO}_{4} \\
(\approx 130)\end{array}$} & $196(\max )$ & 95768 & 4.98 & $n \rightarrow \pi^{*}$ transition \\
\hline & 224.5 & 60356 & 4.78 & $p-\pi$ conjugation \\
\hline & 278 & 5122 & 3.7 & $n \rightarrow \pi^{*}$ transition \\
\hline \multirow{4}{*}{$\begin{array}{l}5.48 \cdot 10^{-5} \\
0.1 \mathrm{M} \mathrm{NaOH} \\
\quad(\approx 80)\end{array}$} & 218 & 33723 & 4.52 & $n \rightarrow \pi^{*}$ transition \\
\hline & $260(\max )$ & 52974 & 4.72 & $n \rightarrow \pi^{*}$ transition \\
\hline & 391.5 & 20000 & 4.3 & $n \rightarrow \pi^{*}$ transition \\
\hline & 405.5 & 20292 & 4.3 & $n \rightarrow \pi^{*}$ transition \\
\hline \multirow{3}{*}{$\begin{array}{c}6.56 \cdot 10^{-5} \\
n \text {-hexane } \\
(1.88)\end{array}$} & $254.5(\max )$ & 3902 & 3.59 & $n \rightarrow \pi^{*}$ transition \\
\hline & 273.5 & 2988 & 3.48 & $n \rightarrow \pi^{*}$ transition \\
\hline & 522 & 1707 & 3.23 & $\pi \rightarrow \pi^{*}$ transition \\
\hline \multirow{4}{*}{$\begin{array}{c}1.67 \cdot 10^{-5} \\
96 \% \text { ethanol } \\
(24.55)\end{array}$} & 202.5 & 58683 & 4.77 & $n \rightarrow \pi^{*}$ transition \\
\hline & 257 (max) & 82934 & 4.92 & $n \rightarrow \pi^{*}$ transition \\
\hline & 381 & 12156 & 4.08 & $n \rightarrow \pi^{*}$ transition \\
\hline & 397.5 & 14132 & 4.15 & $n \rightarrow \pi^{*}$ transition \\
\hline \multirow{4}{*}{$\begin{array}{l}2.24 \cdot 10^{-5} \\
\text { chloroform } \\
\quad(4.81)\end{array}$} & 205 & 9688 & 3.98 & $n \rightarrow \pi^{*}$ transition \\
\hline & $254(\max )$ & 26027 & 4.42 & $n \rightarrow \pi^{*}$ transition \\
\hline & 340 & 937.5 & 2.97 & $n \rightarrow \pi^{*}$ transition \\
\hline & 392 & 4866 & 3.68 & $n \rightarrow \pi^{*}$ transition \\
\hline \multirow{3}{*}{$\begin{array}{l}8.2 \cdot 10^{-5} \\
\text { acetone } \\
(20.56)\end{array}$} & 374.5 & 9012 & 3.95 & $n \rightarrow \pi^{*}$ transition \\
\hline & $392(\max )$ & 12134 & 4.08 & $n \rightarrow \pi^{*}$ transition \\
\hline & 434.5 & 256 & 2.4 & $n \rightarrow \pi^{*}$ transition \\
\hline
\end{tabular}

Table 4

Theoretical spectroscopic study

of 10-((5-mercapto-1,3,4-oxadiazole-2-yl)methyl)-2-methylacridine-9(10H)-one (4a) in Gaussian program

\begin{tabular}{|c|c|c|c|c|c|c|}
\hline \multirow[b]{2}{*}{ Solvent } & \multicolumn{3}{|c|}{ Thione form } & \multicolumn{3}{|c|}{ Thiole form } \\
\hline & $\lambda, \mathrm{nm}$ & $\begin{array}{c}\text { Transition energy } \\
\Delta E, \mathrm{eV}\end{array}$ & $\begin{array}{c}\text { Force } \\
\text { oscillator } f\end{array}$ & $\lambda, \mathrm{nm}$ & $\begin{array}{c}\text { Transition energy } \\
\Delta E, \mathrm{eV}\end{array}$ & $\begin{array}{c}\text { Force } \\
\text { oscillator } f\end{array}$ \\
\hline \multirow{3}{*}{ Acetone } & 327.18 & 3.7895 & 0.0066 & 324.02 & 3.8265 & 0.0003 \\
\hline & 340.20 & 3.6445 & 0.0071 & 346.44 & 3.5788 & 0.0108 \\
\hline & 363.09 & 3.4147 & 0.1079 & 360.12 & 3.4428 & 0.1051 \\
\hline \multirow{3}{*}{ Water } & 326.32 & 3.7995 & 0.0059 & 323.17 & 3.8365 & 0.0003 \\
\hline & 339.32 & 3.6539 & 0.0057 & 345.53 & 3.5882 & 0.0085 \\
\hline & 363.12 & 3.4144 & 0.1082 & 360.31 & 3.4411 & 0.1060 \\
\hline \multirow{3}{*}{ Chloroform } & 330.17 & 3.7552 & 0.0094 & 327.38 & 3.7872 & 0.0004 \\
\hline & 343.21 & 3.6124 & 0.0151 & 349.35 & 3.5490 & 0.0290 \\
\hline & 363.34 & 3.4124 & 0.1019 & 359.89 & 3.4451 & 0.0916 \\
\hline \multirow{3}{*}{ Ethanol } & 333.86 & 3.7136 & 0.0095 & 323.82 & 3.8288 & 0.1059 \\
\hline & 347.39 & 3.5691 & 0.0073 & 346.24 & 3.5809 & 0.0102 \\
\hline & 370.14 & 3.3497 & 0.1045 & 360.21 & 3.4420 & 0.0003 \\
\hline
\end{tabular}


In theoretical spectroscopic studies of the compound 10-((5-mercapto-1,3,4-oxadiazole-2-yl)methyl)- 2methylacridine-9(10H)-one in the polar solvents (Table 4) occurs the influence of the methyl group in the 2-position, as an electron donor for the acridone ring. This appears in a slight bathochromic shift in the spectra of $+5-7 \mathrm{~nm}$ for all wavelengths in polar solvents and lower electron transition energy.

UV-spectra showed the presence of the $\pi$-conjugated system in 1,3,4-oxadiazoles, which is analogous to the benzene aromatic system. But direct reactions of electrophilic substitution on carbon atoms for 1,3,4oxadiazole are unknown due to protonation of the latter in an acid medium and subsequent discovery of the cycle.

For the final confirmation of the thione-thiol tautomerism, we removed the IR-spectra of the corresponding compounds in the solid state (thione form), potassium salts of the corresponding compounds (thiol form), and, accordingly, the difference in the fluctuations of the functional groups of these compounds was found. At the same time, the oscillations were also theoretically calculated for these compounds in the Gaussian program, which completely coincide with the experimental spectra. From the above infrared spectra it is uniquely possible to establish a characteristic thiol group in infrared spectra of potassium salts in the range of $v=3211.98-3212.08 \mathrm{~cm}^{-1}$. The thione form of the solids is evidenced by the presence of vibrations in the range of $v=1290.17-1324.67 \mathrm{~cm}^{-1}$, which corresponds to the strong band, as in the xanthate for the $\mathrm{C}=\mathrm{S}$ group.

In our opinion, the final discovery of the nature of thione-thiol tautomerism is the calculation of electronegativity of atoms and the transition of valence electrons to energy levels.

The calculations of the molecular orbit (MO) have shown that these compounds have complex 389 and 414 occupied molecular orbitals (MO). The highest energy is called the highest occupied molecular orbital (HOMO), and LUMO is the lowest unoccupied molecular orbital. The value of the levels energy of HOMO and LUMO orbitals indicate the reactivity of the molecule as a donor and an electron acceptor.

In addition, HOMO and LUMO orbitals are considered to be important parameters in determining molecular properties [46]. The difference in energy between HOMO and LUMO orbitals is called excitation energy, which indicates the chemical reactivity of the molecule to electronic transport and the establishment of biological activity with intramolecular charge transfer [47, 48]. Table 5 shows the energy of HOMO and LUMO orbitals and their difference in the values of electron transition.

The most advantageous energy transitions of electrons from HOMO to LUMO orbitals of compounds are shown in Fig. 3 with the principle of the least energy for the transition. As it is shown in Fig. 3, the electronic clouds of HOMO orbital energy levels are preferably located on acridine-9(10H)-one and the methylene bond which is an area of the bipolar molecule. Electronic clouds of LUMO orbitals energy levels are mainly concentrated on the nucleus of oxadiazole as a larger acceptor, but also remain on acridine-9(10H)-one.

Proceeding from the above, the density of the electronic basic states of molecular orbitals is mainly localized on the $\pi$-system and on a single pair of S-atoms; respectively, it was found from the UV-spectra that the electronic transition from the main to the excited state would be mixed ( $\pi-\pi^{*}$ and $n-\pi^{*}$ states).
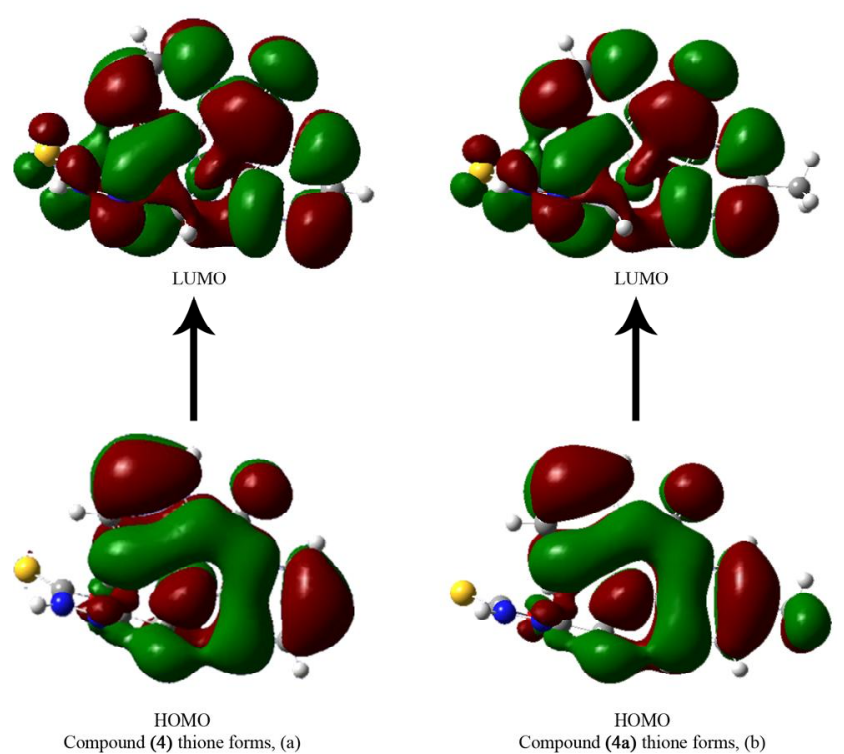

Fig. 4. Energy transitions of electrons from HOMO to LUMO orbitals for 10-((5-thioxo-4,5-dihydro-1,3,4-oxadiazole-2yl)methyl)acridine-9(10H)-one (a) and 10-((5-mercapto-1,3,4oxadiazole-2-yl)methyl)-2R-acridine-9(10H)-ones (b)

Table 5

The energy of HOMO and LUMO orbitals of 10-((5-mercapto-1,3,4-oxadiazole-2-yl)methyl)-2R-acridine-9(10H)-ones

\begin{tabular}{|c|c|c|c|c|}
\hline Compound & Form & EHOMO & ELUMO & $\Delta \mathrm{E}$ \\
\hline $\mathbf{4}$ & thione & -0.2074967090 & -0.0596967610 & 0.147799948 \\
\hline $\mathbf{4}$ & thiol & -0.2069771120 & -0.0584689033 & 0.1485082087 \\
\hline $\mathbf{4 a}$ & thione & -0.2031653220 & -0.0583123042 & 0.1448530178 \\
\hline $\mathbf{4 a}$ & thiol & -0.2026807010 & -0.0570734249 & 0.1456072761 \\
\hline
\end{tabular}



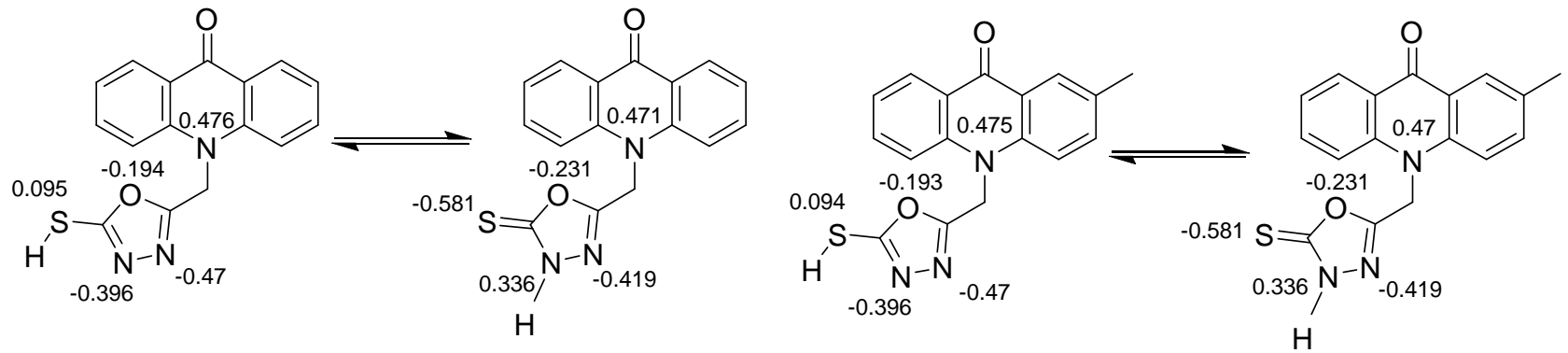

Fig. 5. Charging of atoms of investigating compounds in consideration of thione-thiol tautomerism

Taking into account the electronic structural formulas of the 10-((5-mercapto-1,3,4-oxadiazol-2-yl) methyl)-2R-acridine-9(10H)-ones (Fig. 5) and the results of calculating the atoms charges of the molecule under study, we can conclude that the sulfur atom, due to the acceptor influence of the 1,3,4-oxadiazole ring, is observed to have a shortage of electrons $(+0.094)$. This contributes to the reaction of electrophilic substitution (e.g., alkylation). The high negative charge of the nitrogen unsubstituted atoms of the 1,3,4-oxadiazole ring promotes the conduct of $A_{E}$ reactions. On the contrary, in the thionic form, it is possible to carry out reactions of $S_{\mathrm{E}}$ (for example, acylation) on the nitrogen atom closer to the sulfide group.

Based on the above, it can be said that the new hybrid of 1,3,4-oxadiazole-2-thione with acridine-9(10H)one have significant pharmacological and technical interest. They can be potent biologically active substances with a wide range of effects, and can find their usage in the technical circle in the creation of liquid crystals, LEDs, light emitting diodes and OLEDs.

\section{Conclusions}

It has been investigated that in the neutral solutions (water, ethanol, $n$-hexane) the researched compounds are predominantly in the form of thione, but in alkaline $(0.1 \mathrm{M}$ $\mathrm{NaOH})$ and acid solutions $\left(0.1 \mathrm{M} \mathrm{HCl}\right.$ and $\left.1 \mathrm{M} \mathrm{H}_{2} \mathrm{SO}_{4}\right)$ they extend the form of thiol. Using UV-spectra, it has been established that the electron transition of the methylene bonder of the heterocycles - acridine- $9(10 H)$ one and 1,3,4-oxadiazole - from the main to the excited state will be mixed ( $\pi-\pi^{*}$ and $n-\pi^{*}$ states). It is definitely possible to establish from the IR-spectra a characteristic thiol group for potassium salts of the 10-( 5 -mercapto1,3,4-oxadiazole-2-yl)methyl)-2R-acridine- $9(10 H)$-ones in the range of $v=3211.98-3212.08 \mathrm{~cm}^{-1}$. The thione form of the solids is proved by the presence of vibrations in the range of $v=1290.17-1324.67 \mathrm{~cm}^{-1}$, which corresponds to the strong band, as in the xanthate for the $\mathrm{C}=\mathrm{S}$ group. Taking into account the electronic structural formulas of 10-((5-mercapto-1,3,4-oxadiazole-2-yl)
methyl)-2R-acridine-9(10H)-ones and the results of calculating the charge of atoms of the molecule under study, that on the sulfur atom, due to the acceptor influence of the 1,3,4-oxadiazole ring, there is a shortage of electrons $(+0.094)$. This contributes to the reaction of electrophilic substitution (e.g., alkylation). The high negative charge of nitrogen unsubstituted atoms of the 1,3,4-oxadiazole ring promotes the proceeding of $\mathrm{A}_{\mathrm{E}}$ reactions. On the contrary, in the thionic form, it is possible to carry out reactions of $\mathrm{S}_{\mathrm{E}}$ (for example, acylation) on the nitrogen atom closer to the sulfide group.

\section{References}

[1] Svoboda G., Poore G., Simpson P., Boder G.: J. Pharm. Sci., 1966, 55, 758. https://doi.org/10.1002/jps.2600550803

[2] Shoji A., Hasegawa T., Kuwahara M. et al.: Bioorg. Med. Chem. Lett., 2007, 17, 776. https://doi.org/10.1016/j.bmcl.2006.10.072

[3] Sondhi S., Singh J., Rani R. et al.: Eur. J. Med. Chem., 2010, 45, 555. https://doi.org/10.1016/j.ejmech.2009.10.042

[4] Karpenko Y., Omelyanchik L.: J. Org. Pharm. Chem., 2017, 15, 21. https://doi.org/10.24959/ophcj.17.917

[5] Omel'yanchik L.: Sintez, svoistva i biologicheskaya aktivnost' $\mathrm{N}$ - i S-zameshhennykh akridina, khinolina, piridina. Doctoral thesis, Moskva 1991.

[6] Mayer J.: Acc. Chem. Res., 2011, 44, 36.

https://doi.org/10.1080/1047840X.2011.544635

[7] Maupin C., Castillo N., Taraphder S. et al.: J. Am. Chem. Soc., 2011, 133, 6223. https://doi.org/10.1021/ja1097594

[8] Zhang M.-T., Irebo T., Johansson O., Hammarström L.: J. Am. Chem. Soc., 2011, 133, 13224. https://doi.org/10.1021/ja203483j

[9] Weinberg D., Gagliardi C., Hull J. et al.: Chem. Rev., 2012, 112, 4016. https://doi.org/10.1021/cr200177j

[10] Sobolewski A., Domcke W.: Chem. Phys., 2003, 294, 73. https://doi.org/10.1016/S0301-0104(03)00388-4

[11] Schultz T., Samoylova E., Radloff W. et al.: Science, 2004, 306, 1765. https://doi.org/10.1126/science.1104038

[12] Bach A., Tanner C., Manca C. et al.: J. Chem. Phys., 2003,

119, 5933. https://doi.org/10.1063/1.1603740

[13] Meuwly M., Bach A., Leutwyler S.: J. Am. Chem. Soc., 2001,

123, 11446. https://doi.org/10.1021/ja010893a

[14] Casadesús R., Moreno M., Lluch J.: Chem. Phys., 2003, 290,

319. https://doi.org/10.1016/S0301-0104(03)00173-3

[15] Lima M., Coutinho K., Canuto S., Rocha W.: J. Phys. Chem. A, 2006, 110, 7253. https://doi.org/10.1021/jp060821b

[16] Siwek A., Wujec M., Wawrzycka-Gorczyca I. et al.: Heteroat. Chem., 2008, 19, 337. https://doi.org/10.1002/hc.20433 
[17] Holla B., Shivanda M., Akberali P. et al.: Il Farmaco, 1996, 51, 785.

[18] Shouji E., Buttry D.: J. Phys. Chem. B, 1998, 102, 1444. https://doi.org/10.1021/jp972825+

[19] Katritzky A., Wang Z., Offerman R.: J. Heterocycl. Chem., 1990, 27, 139. https://doi.org/10.1002/jhet.5570270204

[20] Katritzky A., Borowiecka J., Fan W., Brannigan L.: J.

Heterocycl. Chem., 1991, 28, 1139.

https://doi.org/10.1002/jhet.5570280451

[21] Raper E.: Coord. Chem. Rev., 1996, 153, 199.

https://doi.org/10.1016/0010-8545(95)01233-8

[22] Raper E.: Coord. Chem. Rev., 1997, 165, 475.

https://doi.org/10.1016/S0010-8545(97)90167-3

[23] Koparır M., Çetin A., Cansız A.: Molecules, 2010, 10, 475. https://doi.org/10.3390/10020475

[24] Charistos D., Vagenas G., Tzavellas L. et al.: J. Heterocycl. Chem., 1994, 31, 1593. https://doi.org/10.1002/jhet.5570310653

[25] Tsoleridis C., Charistos D., Vagenas G.: J. Heterocycl. Chem., 1997, 34, 1715. https://doi.org/10.1002/jhet.5570340612 [26] Aydogan F., Turgut Z., Öcal N., Erdem S.: Turk. J. Chem., 2002, 26, 159.

[27] Arthur E., Weissberger J.: Technique of Organic Chemistry. Interscience, New York 1971.

[28] Sysoev P.: Sintez heterocyclicheskykh soedinenij na osnove proizvodnykh acridonacetilovykh kyslot: PhD thesis, Moskva 2015. [29] Majumdar P., Pati A., Patra M. et al.: Chem. Rev., 2014, 114, 2942. https://doi.org/10.1021/cr300122t

[30] Oliveira C., Lira B., Barbosa-Filho J. et al.: Molecules, 2012, 17, 10192. https://doi.org/10.3390/molecules170910192

[31] Fröhlichová Z., Tomaščiková J., Imrich I. et al.: Heterocycles, 2009, 77, 1019. https://doi.org/10.3987/COM-08-S(F)80

[32] Barton D., Ollis U.: Obshhaya Organicheskaya Khimiya. Tom 8. Azotsoderzhashhie geterotsikly. Khimiya, Moskva 1985. [33] Bedlovičová Z., Imrich J., Kristian P. et al.: Heterocycles, 2010, 80, 1047. https://doi.org/10.3987/COM-09-S(S)83

[34] Zou X., Lai L., Jin G.: J. Agr. Food Chem., 2002, 50, 3757. https://doi.org/10.1021/jf0201677

[35] Salimon J., Salih N., Yousif E.: Arab. J. Chem., 2010, 3, 205.

https://doi.org/10.1016/j.arabjc.2010.06.001

[36] Frisch Æ.: Gaussian 09W Reference, Gaussian, Inc., Wallingford, CT, 2009.

[37] Gaussian 09, Revision A.02, M. J. Frisch, G. W. Trucks, H. B. Schlegel, G. E. Scuseria, M. A. Robb, J. R. Cheeseman, G. Scalmani, V. Barone, G. A. Petersson, H. Nakatsuji, X. Li, M. Caricato, A. Marenich, J. Bloino, B. G. Janesko, R. Gomperts, B. Mennucci, H. P. Hratchian, J. V. Ortiz, A. F. Izmaylov, J. L. Sonnenberg, D. Williams-Young, F. Ding, F. Lipparini, F. Egidi, J. Goings, B. Peng, A. Petrone, T. Henderson, D. Ranasinghe, V. G. Zakrzewski, J. Gao, N. Rega, G. Zheng, W. Liang, M. Hada, M. Ehara, K. Toyota, R. Fukuda, J. Hasegawa, M. Ishida, T. Nakajima, Y. Honda, O. Kitao, H. Nakai, T. Vreven, K. Throssell, J. A. Montgomery, Jr., J. E. Peralta, F. Ogliaro, M. Bearpark, J. J. Heyd, E. Brothers, K. N. Kudin, V. N. Staroverov, T. Keith,
R. Kobayashi, J. Normand, K. Raghavachari, A. Rendell, J. C. Burant, S. S. Iyengar, J. Tomasi, M. Cossi, J. M. Millam, M. Klene, C. Adamo, R. Cammi, J. W. Ochterski, R. L. Martin, K. Morokuma, O. Farkas, J. B. Foresman, and D. J. Fox, Gaussian, Inc., Wallingford CT, 2016. [38] Tirado-Rives J., Jorgensen W.: J. Chem. Theory Comput., 2008, 4, 297. https://doi.org/10.1021/ct700248k

[39] Rassolov V., Ratner M., Pople J. et al.: J. Comp. Chem., 2001, 22, 976. https://doi.org/10.1002/jcc. 1058

[40] Caricato M.: J. Chem. Theory Comput., 2012, 8, 5081. https://doi.org/10.1021/ct300382a

[41] Pyykko P., Laaksonen L.: J. Phys. Chem., 1984, 88, 4892. https://doi.org/10.1021/j150665a017

[42] Meison S.: Elektronnye Spektry Pogloshheniya

Heterotsiklicheskikh Soedinenij. Khimiya, Moskva 1966.

[43] Zhirov N.: Lyuminofory. Svetyashhiesya Tverdye Sostavy. Gos. izd-vo oboron. prom., Moskva 1940.

[44] http://webbook.nist.gov/cgi/cbook.cgi?ID=C578950\& Mask $=400 \# U V-V i s-S p e c$

[45] Antsyferov Y.: Dielektrycheskye svoistva vodnykh rastorov soley shchelochnykh metalov, halohennoodorodnykh kyslot i shchelochei. PhD thesis, Irkutsk 2006.

[46] Amalanathan M., Rastogi V., Joe I. et al.: Spectrochim Acta A, 2011, 78, 1437. https://doi.org/10.1016/j.saa.2011.01.023

[47] Padmaja L., Ravi Kumar C., Sajan D. et al.: J. Raman Spect., 2009, 40, 419. https://doi.org/10.1002/jrs.2145

[48] Sagdinc S., Pir H.: Spectrochim. Acta A, 2009, 73, 181. https://doi.org/10.1016/j.saa.2009.02.022

Received: January 24, 2018 / Revised: February 06, 2018 / Accepted: June 06, 2018

\section{ЕКСПЕРИМЕНТАЛЬНЕ I ТЕОРЕТИЧНЕ СПЕКТРОСКОПІЧНЕ ДОСЛІДЖЕННЯ ТІОН- ТІОЛЬНОЇ ТАУТОМЕРІЇ НОВИХ ГІБРИДІВ 1,3,4- ОКСАДІАЗОЛ-2-ТІОНУ 3 АКРИДИН-9(10Н)-ОНОМ}

Анотація. Здійснено синтез нових гібридів 1,3,4оксадіазол-2-тіонів з акридин-9(10Н)-оном, структура яких підтверджена за допомогою хромато-мас-спектрометрії, IЧ, ${ }^{1} \mathrm{H},{ }^{13} \mathrm{C}$-спектроскопії. Досліджена тіон-тіольна рівновага у 8 розчинниках з різною діелектричною проникливістю за допомогою УФ-спектроскопії та методами квантової хімії $з$ використанням базисів DFT/B3LYP та HF. Результати експериментальних розрахунків узгоджуються з теоретичними та показали переважання форми тіону. Враховуючи електронні структурні формули та результати розрахунку зарядів атомів сполук, встановлені активні центри для реакиій за механізмом $S_{E} \operatorname{ma} A_{E}$.

Ключові слова: акридин-9(10H)-он, 1,3,4-оксадіазол, 1,3,4-оксадіазол-2-тіон, УФ-спектроскопія, молекулярні орбіталі, квантово-хімічні розрахунки. 